\title{
Care Instability in Nursing Homes; A Qualitative Study
}

\author{
Majid Rahimi, ${ }^{1}$ Reza Fadayevatan, ${ }^{2, *}$ and Heidar Ali Abedi ${ }^{3}$ \\ ${ }^{1}$ Department of Gerontology, University of Social Welfare and Rehabilitation Sciences, Tehran, IR Iran \\ ${ }_{2}$ Iranian Research Center of Aging, Department of Gerontology, University of Social Welfare and Rehabilitation Sciences, Tehran, IR Iran \\ ${ }_{3}$ Iranian Research Center of Aging, Department of Gerontology, University of Social Welfare and Re
Department of Nursing Midwifery, Islamic Azad University, Isfahan Branch, Khorasghan, IR Iran \\ ${ }^{*}$ Corresponding Author: Reza Fadayevatan, Iranian Research Center of Aging, Department of Gerontology, University of Social Welfare and Rehabilitation Sciences, Tehran, IR Iran. \\ Tel:+98-2122180004, E-mail: reza1092@yahoo.com
}

Received 2014 July 1; Revised 2014 August 10; Accepted 2014 September 1.

\begin{abstract}
Background:The use of long-term care services has risen and this trend is expected to continue as the population reaches old age.

Objectives: This study was performed to assess the caring conditions in nursing homes.

Patients and Methods: This study was conducted with a qualitative approach using conventional qualitative content analysis. The study was conducted on 23 Iranian participants including 14 elders and 9 caregivers. Data was collected with unstructured interviews and continued to the point of data saturation. Analysis of data was performed continually and concurrently with data collection through a comparative method.

Results: Three themes emerged from 595 open codes including care as unpleasant task, sustained care and insufficient resources. Ten subthemes indicated participants' experiences and understanding of caring conditions in a nursing home.

Conclusions: The prevailing given care was the routine one with a focus on physical aspects, although there was some psychological care given to the older people. The findings of this research are guidelines for managers and care planners in nursing homes who should pay attention to physical and psychological care needs of older people. In addition, it is important to pay close attention to the needs of caregivers and provision of instructions for treatment, supervision and education of caregivers and medical students to provide a better care.
\end{abstract}

Keywords: Aging, Nursing Home, Qualitative Research

\section{Background}

Elderly people are more liable to chronic illnesses than young people and are at greater risk of having chronic diseases (1). A small portion of older people, who are over 80 years of age, may be involved in acute, chronic and disabling diseases. It puts them at risk of diseases and disability and leads to several complications such as high risk of hospitalization, frequent hospitalizations and referral to nursing homes (2). The trend of older people referrals to nursing homes is increasing in Iran and is observed more among families with inappropriate facilities (3), as their last option. They select this option as a result of high demands imposed to these families' resources (4). Workforce issues, including shortages of physicians and nurses, are a global concern and all administrations should plan to achieve an adequate supply of physicians and nurses and other professionals equipped to meet the demands of its citizens (5). On the other hand, high load of work in nursing homes together with low job dissatisfaction and occupational burnout affect caregivers' caring behaviors (6); therefore, there are concerns about health- care among the residents of nursing homes. Geriatric care, especially among the older people with Alzheimer disease, is more based on physical dimension resulted from acquired experiences and non-professional function. Although the trace of other dimensions of care is somehow observed, it is based on common sense and personal experiences (7). Research showed that in Taiwan and Hong Kong, the main concerns of the older people concerning care in nursing homes were about loneliness, physical misbehavior, social isolation and inadequacy of self-care and decision making (8). In this direction, existence of physical and psychological misbehavior, neglect and low quality of care is also notable (6). Despite recent advancements, long-term care facilities yet face challenges, because they are usually seen as homes which are inappropriate and inadequate to the needs of elderly. This is due to the fact that most of these homes provide very poor care, do not have a multidisciplinary team to assist them and have poor provision of basic hygiene care and nutrition (9). The decrease is in such a way that there is no specific su-

Copyright (C) 2016, Iranian Red Crescent Medical Journal. This is an open-access article distributed under the terms of the Creative Commons Attribution-NonCommercial 4.0 International License (http://creativecommons.org/licenses/by-nc/4.0/) which permits copy and redistribute the material just in noncommercial usages, provided the original work is properly cited. 
Rahimi M et al.

pervision on the type and quality of given care in these centers (10). There is also inadequate evidence about the balance in older people's caring needs and care given by staff in nursing homes (11). Previous studies have shown that nutritional status, cognitive impairment, absence of daily contact with proxies, depression, neuropsychological deficits, incontinence and infections were among some issues mentioned as predictors for deterioration in ADL (Activities of Daily Living) performance of vulnerable older people. Deterioration in ADL would lead to more individual care demands and higher care dependency (12). On the other hand, routine care is considered as an obstacle for administration of appropriate care (13). Therefore, regarding these changes, the care plan should be personal and flexible and clarify the existing gap between the administrated and expected care. Meanwhile, the role of socio-cultural factors and values should not be ignored in the context of care (7). In Iran to the best of our knowledge, there are no studies on the care conditions of elderly people in nursing homes. Therefore, the aim of this study was exploring the care conditions in Iranian nursing homes to improve the quality of care.

\section{Objectives}

This study aimed to clarify the type of care and show caring behaviors of caregivers, given in nursing homes.

\section{Patients and Methods}

This was a qualitative research as an appropriate method to describe life experiences and give a meaning to them. Conventional content analysis was used to analyze the data and clarify older people and caregivers' experiences regarding existing care function in older people residing in nursing homes. In content analysis, the goal is to describe a phenomenon in case when there is no theory related to the phenomenon or there are few evidences (14). We used content analysis as a research method for the subjective interpretation of the content of interview data through a systematic classification process of coding and identifying concepts or patterns (15). The sources of data in the present study were the older people and their caregivers residing in two private and one charity related nursing homes in Isfahan, Iran. Sampling was purposive with maximum variation technique (16) and continued until data saturation, when there was no new primary code in interviews. Among the older people (as the main participants), those who were more than 60 years old and lacked any cognitive diseases and could remember their everyday life experiences were included. Among the care givers, all members of health care team including nursing aids, nurses, physicians, physiotherapists and psychologists were interviewed. Willingness to participate in the study was another inclusion criterion. Their consent was obtained and the interviews were individu- ally conducted in Persian. Twenty-three 20 - 52 minutes interviews were conducted and continued until data saturation (when no new themes were added). Data collection method was deep unstructured interviews whose basic questions were asked based on the research general questions such as "Could you please explain from the time you came here?" or "What do you do in a working day here?" through which the participants' experiences concerning the given care in nursing home were obtained. Researchers took memo writing about the interviews and extracted findings to compare with the obtained concepts. Interviews were conducted in various shifts and the researchers attended the centers in whole shifts to attain participants' viewpoints. The interviews were digitally recorded and transcribed verbatim word for word, and analyzed. To respect the rigor of data and trustworthiness, credibility, transformability, dependability and conformability were considered in the present study (17). To increase reliability, researchers directly communicated with participants to collect data. Interviews transcripts and the list of subcategories and categories were checked by qualitative research experts. In addition, primary codes, obtained during the interviews, were confirmed by the participants through peer review to ensure coding. Two academic members, well acquainted with qualitative research, conducted external reviews. All stages and processes of the study and reports were precisely recorded and best effort was made to record accurate participants' narrations. Analysis stages were conducted in such a way that firstly, the interviews were reviewed several times and meaning units were extracted as codes and noted aside the transcripts. The codes with almost close concepts were categorized in one category. Finally, similar categories were sorted in separate categories. Ethical considerations such as attaining informed consents, explanation of confidentiality and anonymity of the interviews, participants' right to withdraw from the interview and research at any time were respected, based on general ethical guideline for human researches by the ministry of health of Islamic Republic of Iran. Moreover, an informed consent was obtained from each participant included in the study. The ethical approval of the research was taken from ethics committee in University of Social Welfare and Rehabilitation Sciences (May 2013). The researcher was officially introduced to nursing homes and conducted the interviews after attaining permission from the managers of the related nursing homes.

\section{Results}

Twenty-three interviews were conducted of which 14 were conducted with the older people (five males and nine females) and 9 with the caregivers (three nursing aids, two nurses, two managers, and two physicians). The older people mean age was 75.3 years and caregivers' mean work experience was 7.7 years. Regarding 
Rahimi M et al.

caregivers' education, one was illiterate, three had high school diplomas, two had bachelor's degrees, one had a master's degree and two had medical doctorate (Table 1). After precise review of the interviews and extraction of meaning units as codes, 595 open codes were ob- tained that were categorized in ten categories through constant comparison and data analysis, Finally, they yielded three main themes of "care as an unpleasant task," "sustained care" and " insufficient resources" (Table 2).

\begin{tabular}{|c|c|c|c|c|c|}
\hline Code No. & Age/Gender & Marital Status & Previous Living Arrangement & Length of Stay, y & Level of Education \\
\hline EP1 & 61/Male & Widowed & Home-Alone & 1 & Illiterate \\
\hline EP2 & 77/Male & Married & Home-Spouse & 5 & Illiterate \\
\hline EP3 & 69/Female & Widowed & Home-Son & 2 & Illiterate \\
\hline EP4 & 68/Female & Widowed & Home-Alone & 10 & Illiterate \\
\hline EP5 & 64/Female & Widowed & Home-Son & 5 & Elementary \\
\hline EP6 & 82/Female & Widowed & Home-Nephew & 7 & Illiterate \\
\hline EP7 & 92/Male & Single & Home-Alone & 2 & Elementary \\
\hline EP8 & 81/Female & Widowed & Home-Daughter & 1 & Elementary \\
\hline EP9 & 81/Female & Widowed & Home-Son & 2 & Illiterate \\
\hline EP10 & 69/Male & Widowed & Home-Son & 1 & Elementary \\
\hline EP11 & 72/Male & Married & Home-Spouse & 1 & Illiterate \\
\hline EP12 & 66/Female & Widowed & Home-Brother & 2 & Illiterate \\
\hline EP13 & 90/Female & Widowed & Home-Alone & 10 & Illiterate \\
\hline EP14 & 83/Female & Widowed & Home-Son & 2 & Illiterate \\
\hline Mean & 75.3 & & & 3.64 & \\
\hline
\end{tabular}

a Abbreviation: EP, Elder people.

Table 2. Participants' Demographic Characteristics ${ }^{\mathrm{a}}$

\begin{tabular}{lcccc}
\hline Code No. & Age/Gender & Responsibility & Length of working, $\mathbf{~}$ & Level of Education \\
\hline CG1 & 47 Male & Nurse aid & 19 & Illiterate \\
CG2 & 29 Female & Nurse & 5 & Bachelor \\
\hline CG3 & 37 Female & Nurse aid & 4 & Diploma \\
CG4 & 42 Female & Nurse & 8 & Diploma \\
\hline GG5 & 33 Female & Nurse aid & 3 & Elementary \\
\hline CG6 & 31 Female & Manager & 4 & Master \\
CG7 & 35 Female & Physician & 8 & Doctorate \\
CG8 & 46 Male & Physician & 9 & Doctorate \\
Mg1 & 58 Male & Manager & 9 & Bachelor \\
\hline Mean & 39.7 & & 7.7 & \\
\hline
\end{tabular}

${ }^{\mathrm{a}}$ Abbreviations: CG, Care Giver; Mg, Manager. 


\begin{tabular}{l}
\hline Table 3. Formation of the Themes From the Sub-Themes \\
\hline Themes \\
\hline Care as an unpleasant task \\
Indifference toward given services \\
Defective care \\
Not met requirements \\
Sustained care \\
Occupational burnout \\
Disorganized care program \\
Care gap \\
Unstable constructs and processes \\
Insufficient resources \\
Personnel shortage \\
Shortage in equipment and care related facilities \\
Disorganized inspection \\
\hline
\end{tabular}

\subsection{Care as an Unpleasant Task}

During the process of caregiving, there are cases administrated just to have apparently done the duty, and consequently leading to dissatisfaction among the older people. This theme has three subthemes of "indifference toward given services," "not responded requests" and "defective care".

\subsection{Indifference Toward Given Services}

During caregiving, caregivers were indifferent to the problems of the older people and did not take care of them in the way they should have done. It was in such a way that the given service was not complete or not in a correct way and led to dissatisfaction in the older people. One older person concerning the manner of care complained:

"They change our napkins twice a day, once at night and once in the morning. We suffer a lot from wearing these wet napkins, now way they get wet. We expect them to change us three times a day but they change twice. This is not right, they do not care well. The care does not satisfy the patients. What we can do! (interview 10).

Another older person said: "For example, I tell Mr.... , who is in charge of the ward, when I sleep, I sweat a lot, but there is no care in the way there should be (interview 1 ).

\subsection{Not Met Requirements}

There were cases when an older person repeated his or her request for several times, but either nobody cared or the caregivers claimed to have avoided the request or not to give services in that regard. An older person stated: A nurse in response to the question" Is there anybody who does not perform his or her task"? answered: "yes, many times, for example, I say sheets of older people are dirty and should be changed, go and change them. Af- ter a while, when I ask them whether they had done the task, they answer yes. When I check, I see the sheets not changed yet!" (Interview 15).

\subsection{Defective Care}

Defective administration of care had its own reasons. The most prevalent reason for this issue was a shortage in human resources working as caregivers, their low salary and lack of caregivers' education in this regard. In response to the question, "May some care be forgotten for an older person?" A nurse answered: "We finally conclude that those who should give care to them (the clients) should know well about their physical and psychological needs, and even should have already undergone necessary education about how to treat them (the clients)" (Interview 22).

\subsection{Sustained Care}

This theme emerged from participants' narrations concerning the trend of given care. Although most of the caregivers claimed to have done their best in giving care, the older people reported inadequate and unorganized services. This category has four subcategories as follows:

\subsection{Occupational Burnout}

One of the obstacles in giving appropriate care, mentioned by the caregivers, was job burnout resulted from high load of work, shortage of staff and high number of clients that influenced physical, psychological and mental dimensions.

One of the nurse aides stated: "We are sometimes abnormally nervous. Sometimes it happens, of course, this job is also nerve-racking as it highly affects your nerves and spirit. Working with older people is hard. The work here is both dirty and hard. One should try so much to be satisfied with work." (Interview 11).

\subsection{Disorganized Care}

Having a care plan is something which is noted less in nursing homes and leads to further consequences such as inadequate care and dissatisfaction with given services. An older person, in response to the question, "Who takes care of you?" replied:

"I do not know, no idea! the guy in charge of me is Mr. ... and sometimes a women comes and injects me one ampoule".

\subsection{Care Gap}

This includes participants' statements about the group of care, which was not considered or not decided to be administrated. A nurse concerning the effect of nurses' behavior on psychological status of older people said, "We used to have counseling forms before, we would either fill them ourselves or would take them to the garden to get help from nurse aides. It was also a change (fun) 
Rahimi M et al.

for us. However, now, there are many problems. There are many clients and few staff" (Interview 7).

\subsection{Unstable Constructs and Processes}

Regarding sensitivity of care among older people residing in nursing homes, existence of science-based care and treatment management is essential. All ongoing processes should be basically defined and the service in nursing homes should be given accordingly. One of the managers concerning absence of one of the BS nurses in the center explained:

"You see, any center should have a social worker, psychologist or speech therapist. Nevertheless, the budget is limited and we cannot even hire a BS (Bachelor's Degree) nurse."(Interview 20).

\subsection{Insufficient Resources}

An appropriate care needs its basic tools including experienced and skilled personnel and the needed equipment for care. Another important component to be considered is supervision of external inspectors such as social welfare organization, universities of medical sciences and other NGOs (Non-Governmental Organization). There are several problems, which ultimately lead to dissatisfaction of the older people, caregivers and managers with the trend of given services.

\subsection{Personnel Shortage}

Ignoring the profession of rehabilitation and its lack and hiring not experienced persons instead of nurses is one of the issues categorized in this category. In this regard, an older person in response to question, "Why is the service inadequate?" answered, "I do not know, you see, they are very busy, they cannot. I am not alone in this ward, we are about 140 - 150 clients. It is normal, they cannot give service" (Interviews 1 and 4 ).

One of the nurse aides said:

"I am both a father aide and the janitor, as a matter of fact, I am the janitor. Anyhow, every time I saw they were in shortage of personnel, I helped them to let the work go on in 19 years I have been working here." (Interview 3). Shortage in equipment and care related facilities:

One of the other factors influencing the care in nursing homes is shortage of care related equipment.

A nurse complained that: "Unfortunately, we did not have a blood glucose meter in the ward. Mr. ... says anytime you need it, come and get it from me. It is a big problem" (Interview 15).

\subsection{Disorganized Supervision}

The organizations supervising the function of nursing homes have defective communication with these centers and just conduct routine supervisions. A manager stated:

"We have communications with all organizations, the main organization that is in charge of the older people is Social Welfare Organization. We help them. Average of monthly cost of nursing home for an older person is 200 $\$$. Wellbeing organization pays $8-66 \$$ and the rest is paid by charities". (Interview 20).

\section{Discussion}

The present study aimed to investigate the process of care in nursing homes. This qualitative study was conducted to explore participants' experience, with a focus on nursing homes with different managerial methods (through charity and private sectors). We tried to have the highest variety in collection of participants' data.

Based on participants' experiences, three themes of "care as an unpleasant task", "sustained care" and "insufficient resources" were extracted. These three categories are integrated and emerged from individuals' characteristics, existing facilities and methods of management and prevailing beliefs concerning care in nursing homes. As few similar studies have been already conducted in Iran and the existing ones are not as extensive as the present study, our obtained results can be considered as new findings in this context.

\subsection{Indifference Toward Giving Services}

Cases of indifference were observed in the trend of care in nursing homes. The older people complained of indifference and inadequacy in given services. Factors such as shortage of professional and general care facilities and equipment, shortage of workforce and lack of motivation were mentioned as the most important reasons. Longterm care facilities claim to use the most advanced equipment, but many older people believe that older persons' daily life could be described as a life without a future, running the risk of deteriorating, falling into increased dependence and getting closer to death, which can lead to hopelessness, helplessness and depression (18).

\subsection{Not Met Requirements}

There were many complaints about not met requests by older people, for example sometimes older people feel that caregivers fulfill their needs indifferently, especially during eating or providing them with personal health. Consequently, they preferred not to ask for any care from the caregivers (15). Inger et al. argued that older persons experienced good care when staff took their requests and needs seriously, and invited the older person into a relationship. Encounters with staff could reduce the amount of time spent alone and make daily life meaningful for older persons (18).

\subsection{Defective Care}

Defective care is one of the existing problems in nursing homes. It has been argued that certain kinds of jobs tend to generate stress, which in turn may produce serious health, physiological, emotional and behavioral prob- 
Rahimi M et al.

lems. Providing continued care tends to provoke high levels of stress, fatigue, irritation and mood alterations, which negatively affect caregivers' quality of life, as well as the quality of care-taking (19). Moreover, a care plan is the foundation of quality care. It should be realistic, preventive and rehabilitative and performed together with all the parties involved to the care, the client himself or herself and family members or other significant care givers (20).

\subsection{Occupational Burnout}

Taking care of older people residing in nursing homes is a hard work with physical and psychological complications. Gandoy-Crego et al. (19) believed that external factors such as disputes during work lead to occupational burnout among caregivers working in nursing homes. In their study, about one third of caregivers had moderate to high levels of occupational burnout.

\subsection{Disorganized Care Program}

A care plane is essential for quality care. In this regard, the British Geriatric Medicine Association has published a guideline for quality care in nursing homes with emphasis on some issues such as falling down in the elderly, diagnosis and treatment of fecal incontinency, meditational investigations, reduction of psychotropic drugs consumption and end of life care (21).

\subsection{Care Gap}

Ignoring the requests of older people for care is a common phenomenon in nursing homes. Caregivers' ignorance of the needs of older people in nursing homes has been apparent with some findings like injuries to the trunk, head, and/or anogenital regions, functional dependence, depression, history of violence or aggression, behavioral changes, weight loss, pressure ulcers, genital infections, poor hygiene or unclean living conditions (6).

\subsection{Unstable Constructs and Processes}

Instability in a nursing home is a sophisticated phenomenon including high caregivers' work overload, low budget for management and misbehaving with disabled older people in fulfillment of their needs. Individuals in residential care are mostly older, vulnerable and in need of both assistance with ADL and sheltered living because of their physical and cognitive impairments. Residential care facilities in the Netherlands do not provide specialized medical and nursing care; general practitioner is responsible for medical care (22). There are some instances showing this problem. For example, higher job turnover rates in nursing homes have been shown to be associated with worse quality of care, including higher rates of pressure sores, psychoactive drug use and restraint use (6).

\subsection{Personnel Shortage}

If we name care staff as the engine for a nursing home, we have not exaggerated as adequate personnel from qualitative and quantitative aspects can highly affect the care. Rahman and Schnelle believed that two major problems of workforce shortage and high rotation of workforce in nursing homes have resulted in administration of care for those who need it more. He, quoting from Harington, stated that most nursing homes face shortage of care workforce (23). Adequate number of personnel, in addition to being professional in geriatric long-term care, is among the factors leading to high quality of care.

A shortage in care personnel, and consequently, constant staff rotation has also its own disadvantages. High staff turnover rates are associated with poor quality of care. High staff turnover, particularly among licensed nurses, may make it difficult to assess residents and implement care plans, reduce familiarity between staff and residents, making detection of complications and failing health more difficult and affect quality through insufficient supervision and training (21). Moreover, lower staff ratios may similarly diminish care quality, although that may depend on the specific type of staff member (6).

Insufficient care related equipment and facilities: The shortage or uselessness of care equipment is another element affecting the quality of care given to older people in nursing homes as existence of care equipment is essential. Whittaker et al. (24) in their study on end of life care among older people residing in nursing homes mentioned the existing problems as the needed care equipment and inadequate education concerning their use.

\subsection{Disorganized Supervision}

Supervision on the function of nursing homes is the duty of supervising organizations to guarantee the quality of care. Any defect in this field leads to defective cares. In the absence of publicly reported quality information, nursing homes may invest in quality only to the extent that it improves quality that is easily observed by consumers. By public reporting, if reported quality measures successfully differentiate providers based on their performance, nursing homes that score well on publicly reported measures may be financially rewarded, creating an incentive for increased attention to quality (25).

\section{Acknowledgments}

We appreciate contributions of the Department of Gerontology of University of Social Welfare and Rehabilitation Sciences and all older people and caregivers in Sadeghieh, Shahrvandan-e Arshad and Mahd-e Olya nursing homes in Isfahan for their helps and supports.

\section{Footnotes}

Authors' Contribution:Study concept and design: Majid Rahimi, Reza Fadayevatan and Heidar Ali Abedi; acquisition of data: Majid Rahimi; analysis and interpretation of data: Majid Rahimi, Reza Fadayevatan and Heidar Ali Abedi; drafting of the manuscript: Majid Rahimi, Reza 
Fadayevatan and Heidar Ali Abedi; critical revision of the manuscript for important intellectual content: Majid Rahimi; administrative, technical and material support: Majid Rahimi, Reza Fadayevatan and Heidar Ali Abedi; study supervision: Reza Fadayevatan and Heidar Ali Abedi.

Financial Disclosure:This study was funded and supported by the Department of Gerontology of University of Social Welfare and Rehabilitation Sciences.

Funding/Support:This study was funded and supported by the Department of Gerontology of University of Social Welfare and Rehabilitation Sciences.

\section{References}

1. Abedi H, Lali M, Keyvanniya S, Nikbakht A. A study of elderly life experiences as potential conditions for reducing risk factors of chronic diseases. Jundishapur J Chronic Dise Care. 2014;3(2):53-63.

2. Maghsoodnia S. Praimary Health Care for Old Adults in I.R.I. 2th ed. Tehran: U.S.W.R; 2011.

3. Poorreza A, Khabiri R. Economic Health and Ageing. Salmand Iranian JAeing. 2006;1(2):8.

4. Norouzi K, Abedi HA, Maddah Sadat SB, Mohammadi E, Babaee G. Development of a communitybased care system model for senior citizens in Tehran. Int J Adv Nursing Pract. 2006;8:78-85.

5. Tolson D, Rolland Y, Andrieu S, Aquino JP, Beard J, Benetos A, et al. International Association of Gerontology and Geriatrics: a global agenda for clinical research and quality of care in nursing homes. J Am Med Dir Assoc. 2011;12(3):184-9. doi: 10.1016/j. jamda.2010.12.013. [PubMed: 21333919]

6. Lindbloom EJ, Brandt J, Hough LD, Meadows SE. Elder mistreatment in the nursing home: a systematic review. J Am Med Dir Assoc. 2007;8(9):610-6. doi: 10.1016/j.jamda.2007.09.001. [PubMed: 17998119]

7. Yektatalab S, Sharif F, Kaveh MH, Fallahi Khoshknab M, Petramfar P. Living with and caring for patients with Alzheimer's disease in nursing homes. J Caring Sci. 2013;2(3):187-95. doi:10.5681/ jcs.2013.023. [PubMed: 25276726]

8. Hwang HL, Hsieh PF, Wang HH. Taiwanese long-term care facility residents' experiences of caring: a qualitative study. Scand $J$ Caring Sci. 2013;27(3):695-703. doi: 10.1111/j.1471-6712.2012.01082.x. [PubMed: 23043566]

9. Batista MRF, Batista F, Meneses KM, Pompeu LF, Silva RRS, Sousa $\mathrm{CMM}$, et al. Elders` perception of their lives in long-term care facilities. J Nurs UFPE line. 2014;8(7):1988-96.

10. Shah SM, Carey IM, Harris T, DeWilde S, Hubbard R, Lewis S, et al. Identifying the clinical characteristics of older people living in care homes using a novel approach in a primary care database. Age Ageing. 2010;39(5):617-23. doi: 10.1093/ageing/afq086. [PubMed: 20639514]

11. Karlsson S, Edberg AK, Hallberg IR. Professional's and older per- son's assessments of functional ability, health complaints and received care and service. A descriptive study. Int J Nurs Stud. 2010;47(10):1217-27. doi: 10.1016/j.ijnurstu.2010.03.003. [PubMed: 20371057]

12. Caljouw MA, Cools HJ, Gussekloo J. Natural course of care dependency in residents of long-term care facilities: prospective follow-up study. BMC Geriatr. 2014;14:67. doi: 10.1186/1471-2318-1467. [PubMed: 24884563]

13. George J, Munro K, McCaig D, Stewart D. Risk factors for medication misadventure among residents in sheltered housing complexes. Br J Clin Pharmacol. 2007;63(2):171-6. doi:10.1111/j.13652125.2006.02799.x. [PubMed: 17076694]

14. Hsieh HF, Shannon SE. Three approaches to qualitative content analysis. Qual Health Res. 2005;15(9):1277-88. doi: 10.1177/1049732305276687. [PubMed:16204405]

15. Djalali A, Khankeh H, Ohlen G, Castren M, Kurland L. Facilitators and obstacles in pre-hospital medical response to earthquakes: a qualitative study. Scand J Trauma Resusc Emerg Med. 2011;19:30. doi:10.1186/1757-7241-19-30. [PubMed: 21575233]

16. Holloway I, Wheeler S. Qualitative Research in Nursing. Edinburg: Blackwell Co; 2002.

17. Polit DF, Beck CT. Essentials of nursing research : appraising evidence for nursing practice.Philadelphia: Lippincott Williams \& Wilkins; 2010.

18. Inger J, Blomberg K, Kihlgren A. A meaningful daily life in nursing homes - a place of shelter and a space of freedom: a participatory appreciative action reflection study. BMC Nurs. 2014;13:19. doi:10.1186/1472-6955-13-19. [PubMed: 25050083]

19. Gandoy-Crego M, Clemente M, Mayan-Santos JM, Espinosa P. Personal determinants of burnout in nursing staff at geriatric centers. Arch Gerontol Geriatr. 2009;48(2):246-9. doi: 10.1016/j. archger.2008.01.016. [PubMed: 18359109]

20. Julin Y, Leena M. Admission to the Elderly Care Home and the Transition Experience: A Literature Review. Finland Arcada Univ Appl Sci. 2014.

21. Thomas KS, Mor V, Tyler DA, Hyer K. The relationships among licensed nurse turnover, retention, and rehospitalization of nursing home residents. Gerontologist. 2013;53(2):211-21. doi: 10.1093/ geront/gns082. [PubMed: 22936529]

22. van der Ploeg ES, Bax D, Boorsma M, Nijpels G, van Hout HP. A cross-sectional study to compare care needs of individuals with and without dementia in residential homes in the Netherlands. BMC Geriatr. 2013;13:51. doi:10.1186/1471-2318-13-51. [PubMed: 23706150]

23. Rahman AN, Schnelle JF. The nursing home culture-change movement: recent past, present, and future directions for research. Gerontologist. 2008;48(2):142-8. [PubMed: 18483426]

24. Whittaker E, George Kernohan W, Hasson F, Howard V McLaughlin D. The palliative care education needs of nursing home staff. Nurse Educ Today. 2006;26(6):501-10. doi: 10.1016/j. nedt.2006.01.004. [PubMed:16517029]

25. Park J, Konetzka RT, Werner RM. Performing well on nursing home report cards: does it pay off? Health Serv Res. 2011;46(2):53154. doi:10.1111/j.1475-6773.2010.01197.x. [PubMed:21029093] 